University of Wollongong

Research Online

Faculty of Engineering and Information

Faculty of Engineering and Information

Sciences - Papers: Part B

Sciences

2019

Torque response characteristics of a controllable electromagnetic damper

for seat suspension vibration control

Pengfei Liu

Hefei University of Technology

Xiangjun Xia

Hefei University of Technology

Nong Zhang

Hefei University of Technology, University of Technology Sydney, nong.zhang@uts.edu.au

Donghong Ning

University of Wollongong, Hefei University of Technology, dning@uow.edu.au

Minyi Zheng

Hefei University of Technology

Follow this and additional works at: https://ro.uow.edu.au/eispapers1

Part of the Engineering Commons, and the Science and Technology Studies Commons

Research Online is the open access institutional repository for the University of Wollongong. For further information contact the UOW Library: research-pubs@uow.edu.au 


\title{
Torque response characteristics of a controllable electromagnetic damper for seat suspension vibration control
}

\author{
Abstract \\ In this paper, a novel resistance switching method is proposed to control an electromagnetic damper \\ (EMD) system of a vehicle seat suspension, and torque response characteristics of the EMD system are \\ investigated in detail. First, the relationship between electromagnetic torque and circuit resistance of the \\ EMD system is established. The basic parameters of the EMD system are identified by least squares \\ fitting, and the resistance distribution is optimized to meet the demand damping of seat suspension. \\ Second, the electromagnetic torque response time and the continuously dynamic torque tracking \\ performance of the EMD system are investigated experimentally. The time required for the torque change \\ from its initial to $80 \%$ of the final state and the final state is measured, respectively. The results show that \\ the response time required for torque decrease is shorter than the response time required for torque \\ increase; the EMD system has excellent torque response and torque tracking performance and is suitable \\ for seat suspension vibration control. Finally, two typical vehicle body vibration excitations are exerted on \\ the EMD seat suspension. The test results verify that the EMD seat suspension has excellent controllable \\ damping and can significantly isolate the vibration of driver body when applying a sliding mode control \\ method.

\section{Disciplines} \\ Engineering | Science and Technology Studies

\section{Publication Details} \\ P. Liu, X. Xia, N. Zhang, D. Ning \& M. Zheng, "Torque response characteristics of a controllable \\ electromagnetic damper for seat suspension vibration control," Mechanical Systems and Signal \\ Processing, vol. 133, pp. 106238-1-106238-17, 2019.
}




\title{
Torque response characteristics of a controllable electromagnetic
}

\section{damper for seat suspension vibration control}

\author{
Pengfei Liu ${ }^{1}$, Xiangjun $\mathrm{Xia}^{1}$, Nong Zhang ${ }^{1,3}$ Donghong Ning, ${ }^{2,4, *}$, Minyi Zheng ${ }^{1, *}$ \\ ${ }^{1}$ School of Automotive and Transportation Engineering, Hefei University of Technology, Hefei, 230000, China \\ ${ }^{2}$ School of Mechanical Engineering, Hefei University of Technology, Hefei, 230000, China \\ ${ }^{3}$ School of Mechatronics and Intelligent Systems, Faculty of Engineering, University of Technology Sydney, Sydney, NSW \\ 2007, Australia \\ ${ }^{4}$ School of Electrical, Computer and Telecommunications Engineering, University of Wollongong, NSW 2522, Australia \\ *donghongning@gmail.com; zheng_minyi@hfut.edu.cn
}

Abstract: In this paper, a novel resistance switching method is proposed to control an electromagnetic damper (EMD) system of a vehicle seat suspension, and torque response characteristics of the EMD system are investigated in detail. First, the relationship between electromagnetic torque and circuit resistance of the EMD system is established. The basic parameters of the EMD system are identified by least squares fitting, and the resistance distribution is optimized to meet the demand damping of seat suspension. Second, the electromagnetic torque response time and the continuously dynamic torque tracking performance of the EMD system are investigated experimentally. The time required for the torque change from its initial to $80 \%$ of the final state and the final state is measured, respectively. The results show that the response time required for torque decrease is shorter than the response time required for torque increase; the EMD system has excellent torque response and torque tracking performance and is suitable for seat suspension vibration control. Finally, two typical vehicle body vibration excitations are exerted on the EMD seat suspension. The test results verify that the EMD seat suspension has excellent controllable damping and can significantly isolate the vibration of driver body when applying a sliding mode control method.

Keyword: seat suspension, electromagnetic damping, response performance, semi-active, sliding mode control.

\section{Introduction}

8 Seat suspension is essential to vehicle seat vibration reduction. Vehicle seat with sound vibration reducing performance can reduce the driver's low back pain and improve driving safety $[1,2]$. Most 
recently, the vibration isolation performance and control methods of the seat suspension based on new materials $[3,4]$ and new configurations [5] in the vertical and horizontal directions $[6,7]$ have become research hotspots. Seat suspensions with variable damping and stiffness characteristics have been proven to have superb vibration damping performance $[8,9]$. The fast response performance of the semi-active seat suspension system is the fundamental guarantee of the excellent damping characteristics, and also directly affects the control strategy and control effect of the suspension system [10]. Therefore, the torque response characteristic is an indispensable research point for a controllable suspension, and there are many studies on the response of MR [11, 12]. Koo et al. [13] provided a comprehensive review on the response time of magnetorheological (MR) damper and they defined the response time as the time required from the initial state to $95 \%$ of the final state. Sahin et al. [14] found that MR valves with annular flow geometry have a slower falling response time compared to their rising response time, and MR valves with radial flow geometry demonstrated faster pressure response time both in rising and in falling states. Strecker et al. [15-17] demonstrated that eddy currents in MR damper coils are factors that result in longer MR damper response times. Then they pointed out that the response time of the MR damper has a significant effect on the control effect of the suspension, and proposes an optimized design method.

Electromagnetic devices convert mechanical energy into electrical energy by electromagnetic induction and are widely used in power generation or energy feeding systems [18]. With the deepening of people's understanding of the electromechanical simulation theory, people are paying more and more attention to the structural vibration control using various electromagnetic devices and their constituent circuit systems $[19,20]$. Buelga et al. [21, 22]analyzed the development of electromagnetic dampers (EVAs) with energy recovery and frequency tuning control capabilities. Yang et al. [23] proposed a negative impedance converter with voltage reversal to partially cancel the inherent resistance of the electromagnetic shunt damper circuit and confirmed the superiority of using a negative impedance converter through experiments. Ning et al. [24, 25] designed an electromagnetic damper (EMD) system to replace the hydraulic shock absorber. The permanent magnet synchronous motor is installed in the center of the suspension structure of the commercial vehicle seat suspension, and the vibration of the seat suspension is reduced by using the equivalent resistance value of the PWM signal control circuit.

The above work is a study of the function and control strategy of the EMD system, and there is no research report on the electromagnetic torque response performance. In this paper, the resistance 
switching method is used to control the damping of the EMD system, and the damping torque response characteristics of the EMD system are studied in detail. Taking the permanent magnet synchronous motor (PMSM) speed and electromagnetic torque range of the EMD system as the control object, the time required for the torque to change from its initial state to the final state and the final state of $80 \%$ is analyzed, and the factors affecting the electromagnetic torque response time are studied. Then the dynamic torque following experiment is designed to examine the tracking characteristics of the target torque of different frequencies of the EMD system through the phase difference. Finally, two typical vehicle body vibration excitations are applied to the EMD seat suspension to verify its damping controllability and vibration isolation performance.

The main contributions of this paper are:

- A novel resistance switching method is proposed to change the resistance in the circuit of the EMD system.

- The response time and dynamic tracking performance of the EMD system are investigated.

- A sliding mode controller (SMC) is designed for the EMD seat suspension.

The rest of the paper is organized as following: Section 2 is mainly to complete the design of the EMD system and basic parameter identification; in Section 3 the response time and force tracking performance of the EMD system are analyzed; in Section 4, SMC is designed and validated for EMD seat suspension; finally, a conclusion is to draw in Section 5.

\section{EMD system design and parameter identification}

This section presents the design of the EMD system, the relationship between electromagnetic torque and external resistance is established based on the PMSM power-generation model; the basic parameters of the EMD system are identified.

\subsection{EMD system design}

The electromagnetic damping controllable seat suspension structural is shown in Figure 1. The PMSM of the EMD system is rotated through a planetary gearbox which is installed in the center of the seat scissors structure. When the upper plane of the seat vibrates relative to the vehicle body, the EMD system generates a damping torque that suppresses the vibration of the seat. 


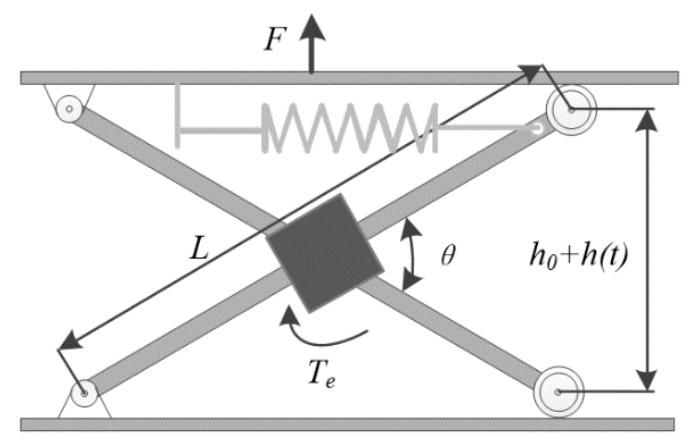

Figure 1. EMD seat suspension structure.

The vertical force generated by the EMD system is:

$$
F=\frac{2 r_{g}}{\sqrt{L^{2}-\left(h_{0}+h\right)}} T_{e}
$$

where the $r_{g}$ is the transmission ratio of the planetary gearbox, the $T_{e}$ is electromagnetic torque of the EMD system, the $F$ is damping force that generates by EMD system, $h$ is vibration amplitude of the seat, $h_{0}$ is the initial height of the seat..

As shown in Figure 2, the EMD system is composed of a PMSM (MSMJ042G1U), a three-phase rectifier, and a resistance controllable unit (RCU). The RCU is connected in series with five MOSFETs (IRF1010) and four different resistors. The damping of the electromagnetic suspension is adjusted by the controller giving a high-level or low-level signal to control the RCU resistance value switching.

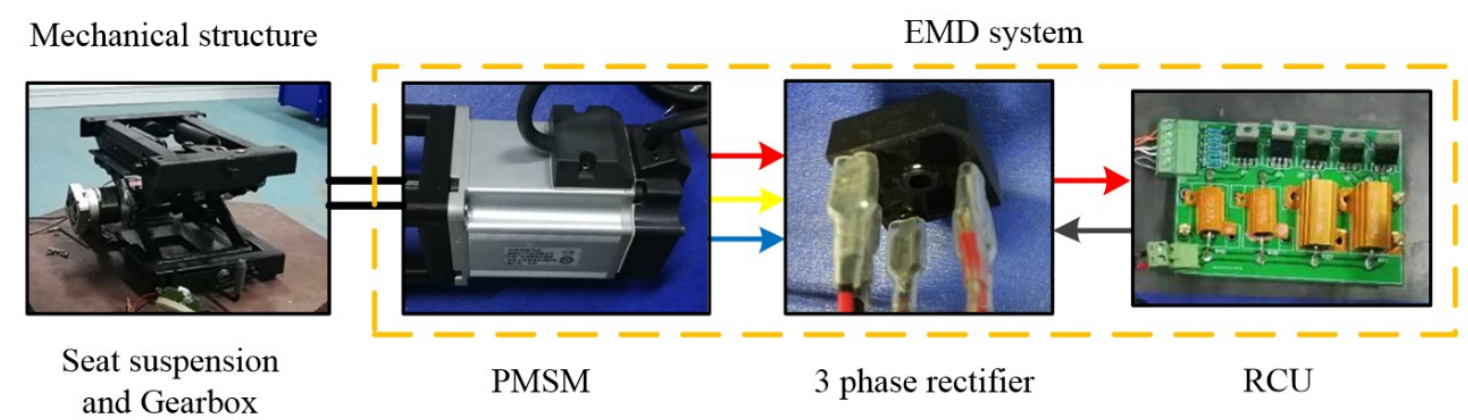

Figure 2. The composition of the EMD seat suspension.

The EMD system theoretical model is shown in Figure 3. The PMSM is simplified as three internal voltage source $\left(e_{a}, e_{b}, e_{c}\right)$, three internal resistances $\left(R_{i a}, R_{i b}, R_{i c}\right)$, and three inductors $\left(L_{i a}, L_{i b}\right.$, $\left.L_{i c}\right)$. The five MOSFET switches are all controlled by digital signals with high-level $(10 \mathrm{~V})$ and lowlevel $(0 \mathrm{~V})$. Since the MOSFET has two states, theoretically, the designed EMD system can realize 32 kinds of different resistance values. 


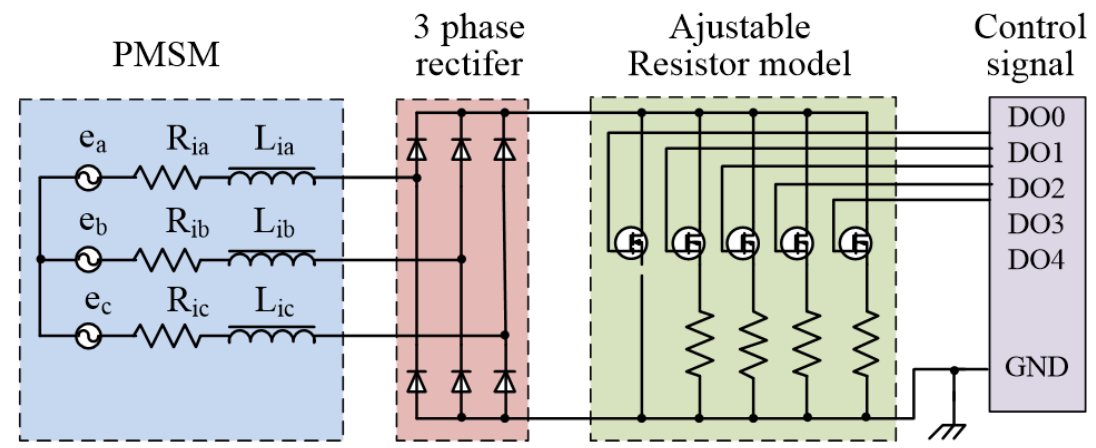

Figure 3. The theoretical model of the EMD system.

The relationship of voltage, current, and flux in the d-q coordinate system of the PMSM is:

$$
\left\{\begin{array}{c}
u_{d}=\left(R_{i}+R_{e}\right) i_{d}+L_{d} \frac{d i_{d}}{d t}-\omega_{e} L_{q} i_{q} \\
u_{q}=\left(R_{i}+R_{e}\right) i_{q}+L_{q} \frac{d i_{q}}{d t}+\omega_{e} L_{d} i_{d}+\omega_{e} \psi_{f}
\end{array}\right.
$$

4 where $u_{d}, u_{q}, i_{d}, i_{q}, L_{d}, L_{q}$ are the voltages, currents and inductances in the d-q axis coordinate system respectively, $R_{i}$ is the internal stator resistance of PMSM, $R_{e}$ is the resistance of the external controllable resistor module, $\psi_{f}$ is the permanent magnet flux linkage, and $\omega_{e}$ the electrical angular velocity of the motor.

The electromagnetic torque can be calculated by:

$$
T_{e}=\frac{3}{2} p_{n} i_{q}\left[i_{d}\left(L_{d}-L_{q}\right)+\psi_{f}\right]
$$

where $T_{e}$ is the electromagnetic moment, $P_{n}$ is the number of rotor pole pairs of PMSM.

When the PMSM is used as a generator, the voltage values $\left(u_{d}\right.$ and $\left.u_{q}\right)$ are zero. Ignoring the difference in the inductance of the d-q axis, $L_{d}=L_{q}=L_{s}$ can be obtained. At the same time, because the seat suspension has high magnitude vibrations at frequencies of $0.4-5 \mathrm{~Hz}$ and the rotor speed is within $\pm 2000 \%$ s, the first order derivative of the current in terms of time in the circuit can be ignored. By combining Equations (2) and (3), the electromagnetic torque can be obtained:

$$
T_{e}=\frac{3}{2} \frac{p_{n}^{2} \psi_{f}^{2}}{\left(R_{i}+R_{e}\right)+\frac{p_{n}^{2} \omega_{m}^{2} L_{s}^{2}}{R_{i}+R_{e}}} \omega_{m}
$$

where $\omega_{m}$ is the rotational speed of the rotor.

The $L_{s}^{2}$ value is small, the term related to the rotational speed in the denominator of Equation (4) tends to be zero when the rotor speed is small. According to the PMSM rotor speed range in the EMD system of the seat suspension, the relationship between the electromagnetic torque and the rotational speed can be simplified: 


$$
T_{e} \approx-\frac{3}{2} \frac{p_{n}^{2} \psi_{f}^{2}}{\left(R_{i}+R_{e}\right)} \omega_{m}=-\frac{3}{2} \frac{k_{t}^{2}}{\left(R_{i q}+R_{e}\right)} \omega_{m}=c_{t} \omega_{m}
$$

1 where $R_{i q}$ is the equivalent internal resistance, $k_{t}$ is the torque constant, $c_{t}$ is the equivalent

2 electromagnetic damping coefficient.

\subsection{EMD system parameter identification}

An experiment platform is established to identify the EMD system parameter, as shown in Figure 4. It consists of a drive motor, a torque sensor, an EMD system, and a controller. The controller adopts industrial-grade NI RIO hardware platform, including cRIO-9067 chassis and four c modules, namely c9401, c9025, c9229, and c9227. As shown in Figure 5, c9401 is used to control the drive motor and measure the rotary speed of PMSM; c9025 is used to measure the signal of the torque sensor; c9229 and c9227 are used to measure the voltage and current of the external resistance, respectively. The data communication between the controller and the PC is completed through LAN communication. A LabVIEW program on the PC is to achieve the human-computer interaction and recording of the above parameters. The EMD system experimental platform can ensure sampling frequency of all signals is 10 $\mathrm{kHz}$, and the simultaneous recording frequency of each signal to the $\mathrm{PC}$ is $500 \mathrm{~Hz}$.

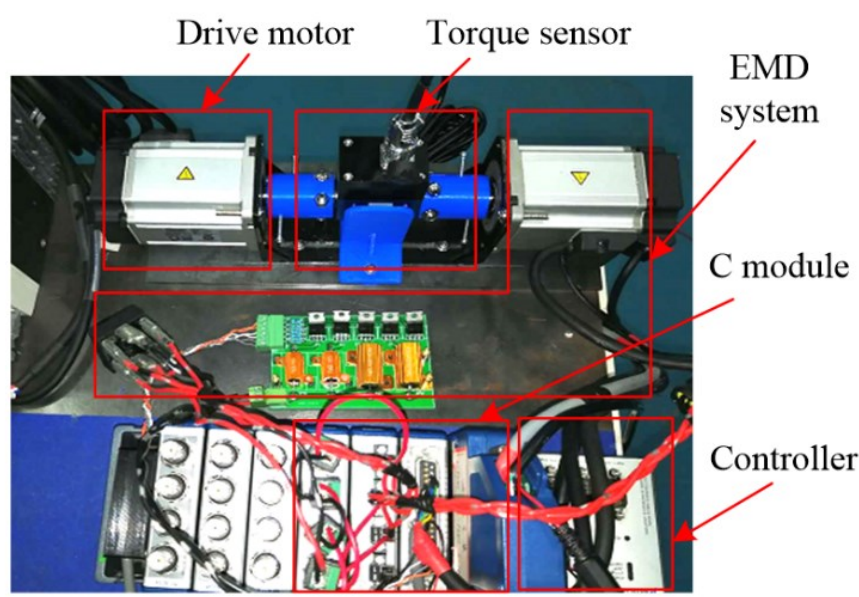

Figure 4. The EMD system test platform. 


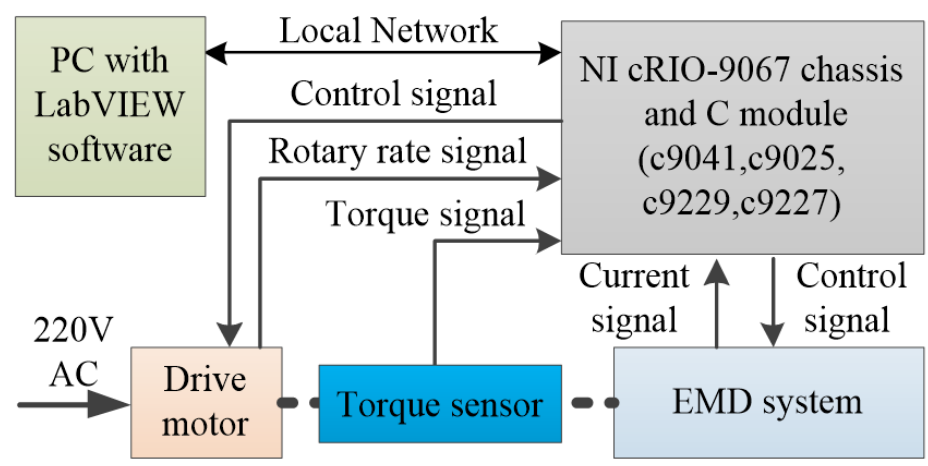

Figure 5. The EMD system test platform framework.

3 To meet the requirement of the EMD seat suspension in damping force, we distribute the 4 electromagnetic damping generated by the PMSM evenly within its range. Firstly, the distribution of 532 kinds of ideal resistances for the seat suspension is obtained from Equation (5). Next, four (between 60 to $50 \Omega$ ) resistances arrangement combinations are selected, and the 32 kinds of actual resistance 7 values are calculated. Finally, root-mean-square value (RMS) of the resistance difference between the 8 ideal resistance values and the actual resistance values are chosen from the 32 arrangements can be 9 calculated. The arrangement with the smallest RMS is the optimal resistance combination $(3 \Omega, 12 \Omega$, $1030 \Omega$ and $50 \Omega$ ) for the RCU. External resistance optimization flowchart is characterized in Figure 6.

11 The curve of the ideal damping and the electromagnetic damping is illustrated in Figure 7.

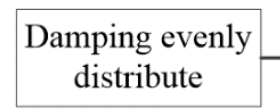
distribute

\section{Ideal resistance evenly distribute}

\section{Calculate actual}

resistance distribute

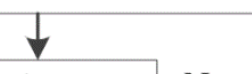

Is RMS of the resistance difference is minimum?

$$
\downarrow \text { Yes }
$$

Obtain the optimal

resistance combination 


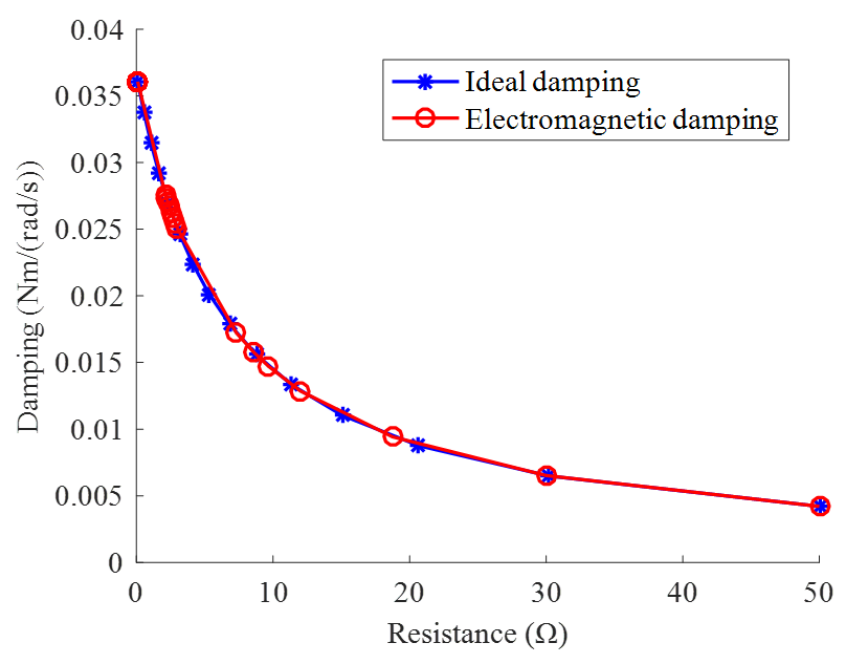

Figure 7. The curves of ideal and electromagnetic damping.

3 The RCU is controlled to switch to different resistance values when the PMSM is driven to rotate 4 in a sinusoidal motion (the frequency is $1 \mathrm{~Hz}$, and the amplitude is $300^{\circ}$ ). The relationship between 5 electromagnetic torque with the rotor angle curve and the rotor angle rate curve are shown in Figure 8 6 and Figure 9, respectively. The results indicate that it is effective to control the electromagnetic torque 7 of the EMD system by resistance switching method.

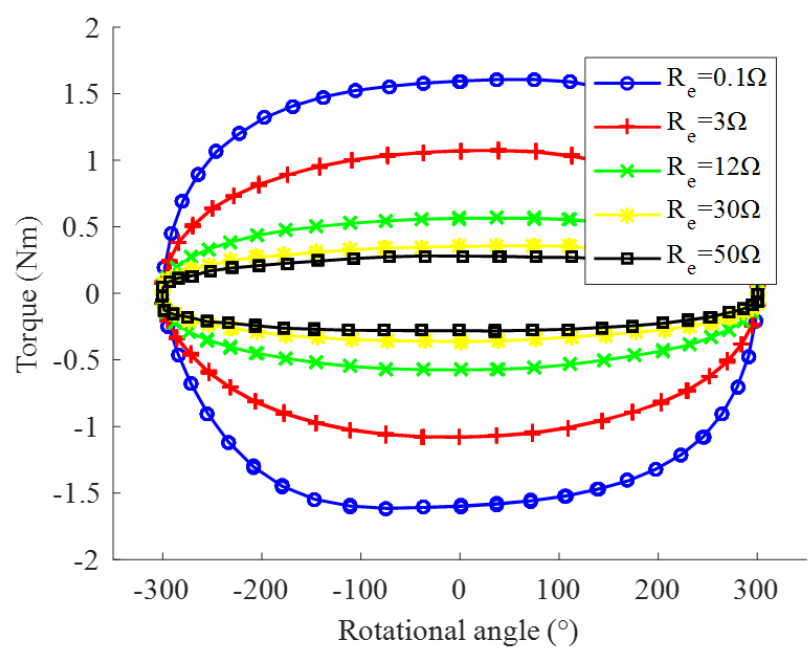

Figure 8 . The relationship between torque and angle. 


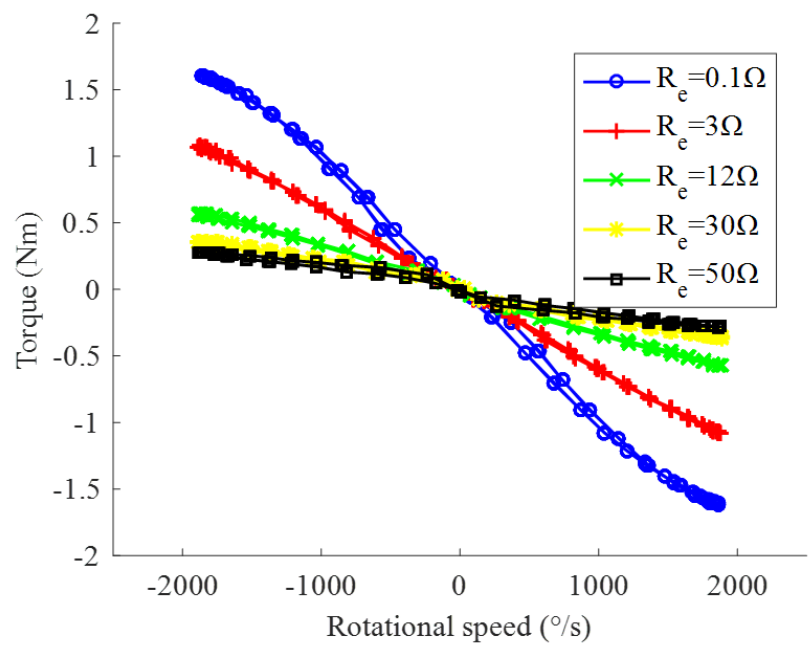

Figure 9. The relationship between torque and speed.

Besides, the RCU is controlled to switch to 5 different resistance values when the motor drives the PMSM to rotate at ten constant speeds between $400-2200 \%$. At the same time, the mechanical friction and air gap damping torque of EMD were measured when the external circuit is open. Remove friction and air gap damping torque of EMD, the relationship between electromagnetic torque and rotational speed curve of EMD are shown in Figure 10 with five different external resistances.

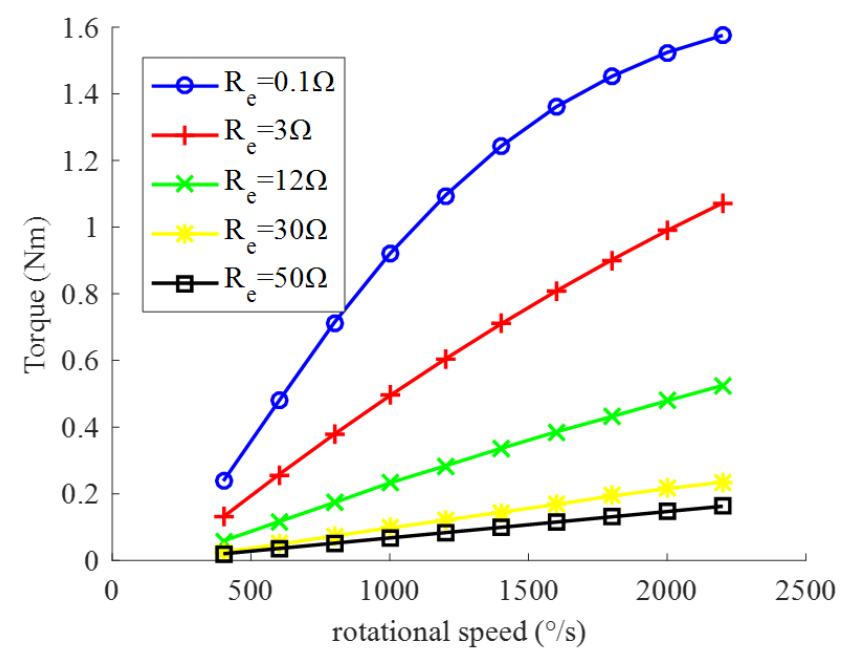

Figure 10. The electromagnetic torque and rotational speed curve

The least square fitting method is used to fit the results of multiple test data; basic parameters of the EMD system can be obtained and are shown in Table 1.

Table 1 Basic parameters of EMD system.

\begin{tabular}{ccc}
\hline \hline Parameter & Symbol & Value \\
\hline Equivalent resistance & $R_{i q}$ & $6.5063 \Omega$ \\
\hline \hline
\end{tabular}




\begin{tabular}{ccc}
\hline \hline Torque constant & $k_{t}$ & $0.48795 \mathrm{Nm} / \mathrm{rad}$ \\
Pole logarithm & $p_{n}$ & 5 \\
Friction torque & $T_{0}$ & $0.045 \mathrm{Nm}$ \\
Damping & $B$ & $0.001 \mathrm{Nm} * \mathrm{~s} / \mathrm{rad}$ \\
\hline \hline
\end{tabular}

\section{Response performance analysis}

2

This part mainly studies the torque response characteristics and the dynamic torque tracking performance of the EMD system by experiments.

\subsection{Response time analysis}

In the experiments for investigation electromagnetic torque response time, the PMSM of EMD system is rotated by the drive motor at a constant rotary speed, and the controller switches the external resistance. The resistance value, the torque signal, and the current signal of the EMD system are recorded synchronously. Figure 11 shows the resistance switching moment, electromagnetic torque, and current curve when the rotational speed is at $1000 \%$ s. The result proved that the electromagnetic torque generated by the EMD system and the current in the circuit have the same response characteristics. Therefore, the response time of the current is also analyzed to reduce the error of the research results.

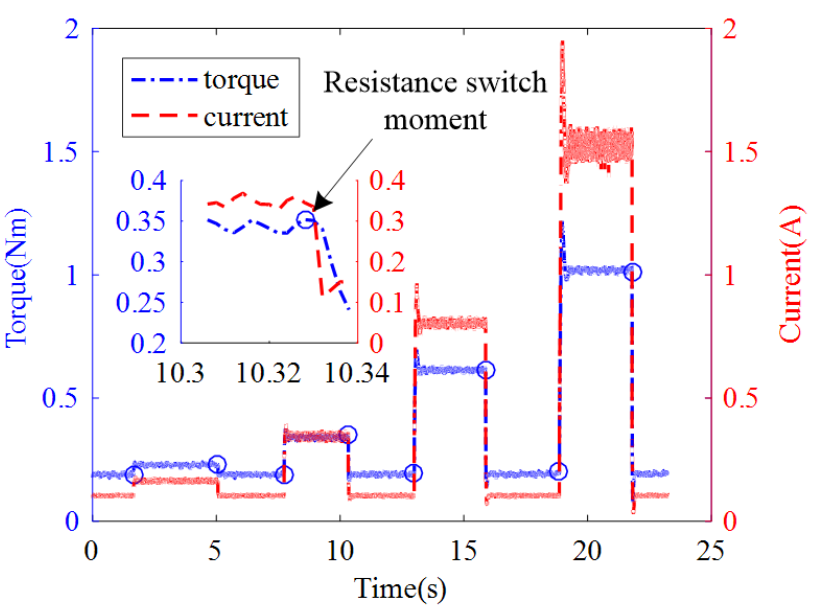

Figure 11. The EMD system torque and current curve.

The moment of resistance switch is defined as an initial state, and the moment of electromagnetic torque reaches a final constant value is defined as a final state. There are four symbols $\left(T_{r}, T_{f}, T q_{r}\right.$, $\left.T q_{f}\right)$ are defined to represent response time of electromagnetic torque under different states. The time from the initial state to the final state when the electromagnetic torque increases and decreases are 
1 defined as $T_{r}, T_{f}$ respectively. When the electromagnetic torque increases and decreases, the time of

2 from the initial state to the $80 \%$ of the final state are defined as $T q_{r}, T q_{f}$ respectively.

3 To analyze the response time of torque and current under a specific working condition, the 4 resistance value, torque, and current signal data are normalized. Figure 12 shows the response time of 5 electromagnetic torque increasing when the resistance value is changed from $50 \Omega$ to $3 \Omega$, and the motor 6 rotary speed is $1000 \%$ s. Figure 13 shows the response time of electromagnetic torque decrease when 7 the resistance value is changed from $3 \Omega$ to $50 \Omega$. It can be seen that in the EMD system, the response 8 time $T_{f}$ is significantly shorter than $T_{r}$.

9

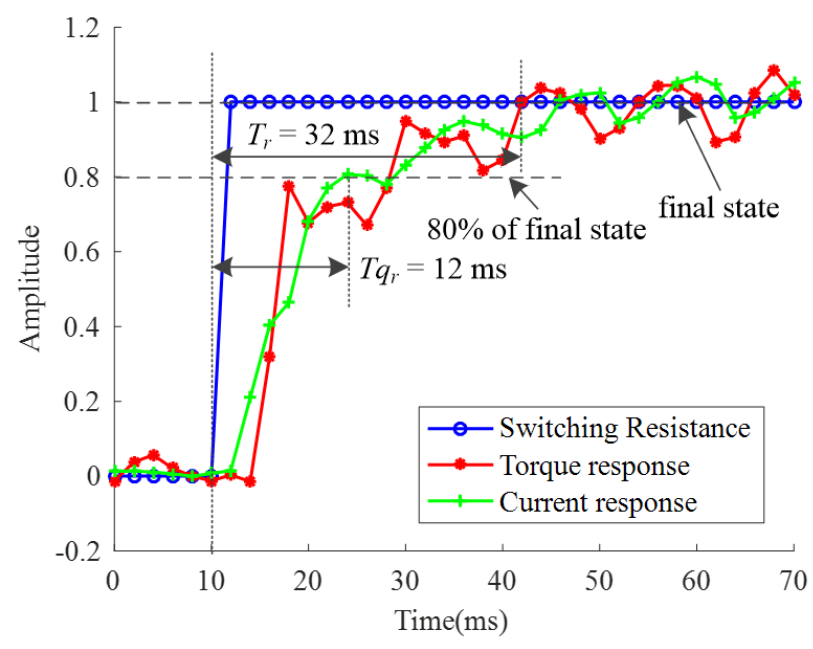

Figure 12. Torque and current increase process curve.

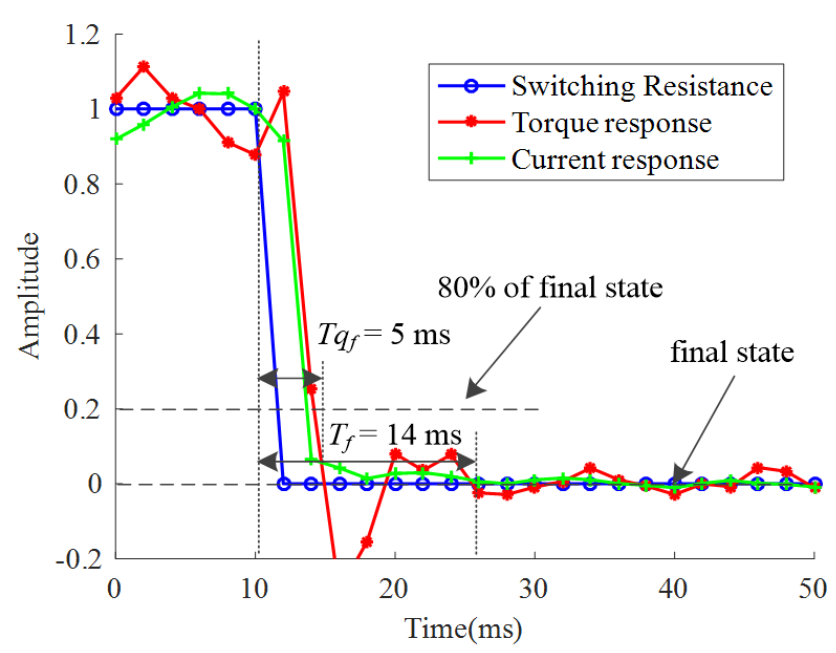

Figure 13. Torque and current decrease process curve.

Besides, although the response time of the current and torque in the EMD system is consistent, the 14 response time fluctuation of current is smaller, which may be caused by the mechanical noise and the 
1 connection preload which has affected the torque measurement result. Therefore, the response time of

2 the current in the EMD system is used to evaluate the response time of the torque in the following

3 statistical analysis. When the PMSM rotational speed is $1000^{\circ} / \mathrm{s}$, the response time with different

4 electromagnetic torque alter ranges $\left(\Delta T_{e}\right)$ is shown in Table 2.

Table 2 The statistical result of torque response time.

\begin{tabular}{ccccc}
\hline \hline$\Delta T_{e}(\mathrm{Nm})$ & $T_{r}(\mathrm{~ms})$ & $T q_{r}(\mathrm{~ms})$ & $T_{f}(\mathrm{~ms})$ & $T q_{f}(\mathrm{~ms})$ \\
\hline 0.1518 & 28 & 10 & 18 & 4 \\
0.4308 & 32 & 12 & 21 & 4 \\
0.8591 & 41 & 18 & 22 & 5
\end{tabular}

6

7

8

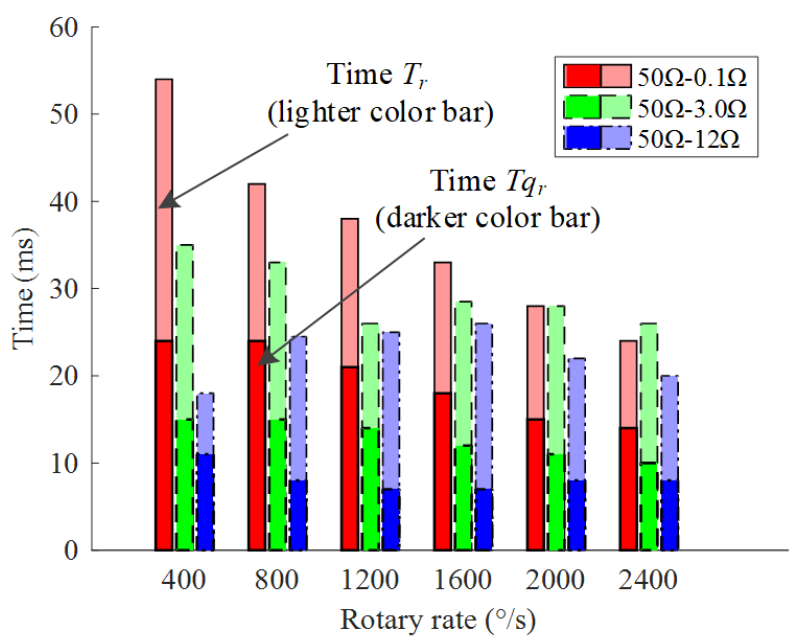

Figure 14. Response time statistics when torque increases. 


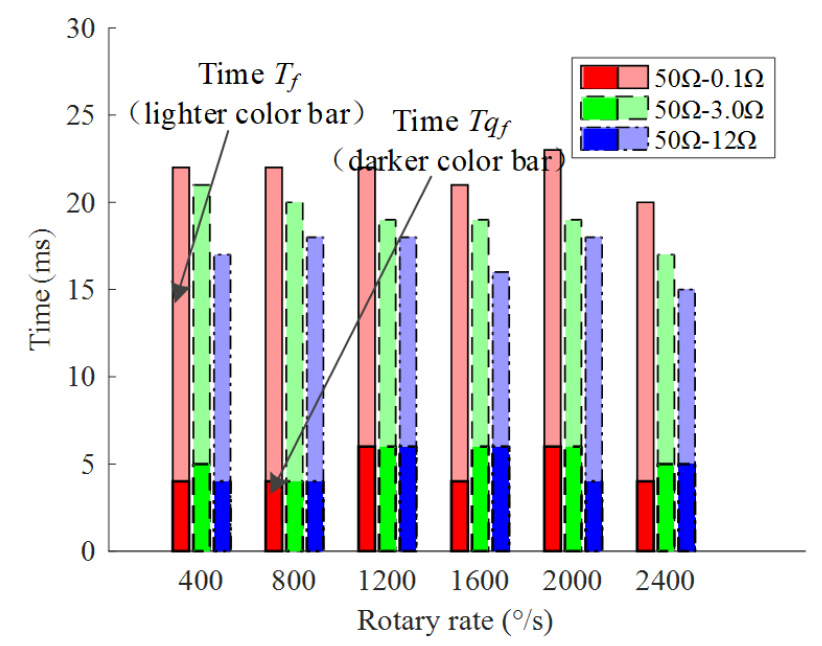

Figure 15. Response time statistics when torque decrease.

Figure 14 indicates that the response time $T_{r}$ and $T q_{r}$ is shorten when increase rotary speed of PMSM. And the response time $T_{r}$ and $T q_{r}$ are tend to be stable when the PMSM rotational speed is above $1600^{\circ} / \mathrm{s}$, which are about $25 \mathrm{~ms}$ and $10 \mathrm{~ms}$ respectively. It can be obtained from Figure 15 that increasing the rotational speed of the PMSM has little effect on the time $T_{f}$ and $T q_{f}$, and they stable at around $20 \mathrm{~ms}$ and $5 \mathrm{~ms}$ respectively. In addition, comparing the two figures, we can find that when the electromagnetic torque increases, the value of $T q_{r}$ is about half of the value of $T_{r}$, and when the electromagnetic torque is decreased, the value of $T q_{f}$ is about a quarter of the value of $T_{f}$. The results characterize that the electromagnetic torque of the EMD system increases or decreases to $80 \%$ of the target torque value, with a relatively short time, hence it has a good torque response performance and meet the requirements for suspension systems vibration control.

\subsection{Tracking performance analysis}

A dynamic torque tracking experiment is designed to research the continuous torque variation of the EMD system. Similarly, the PMSM of the EMD system is rotated by the drive motor at a constant speed, and a target torque curve with adjustable frequency is designed. According to Equation (5), the external resistance value can be obtained to make the electromagnetic torque of the EMD system equal to the target torque. Then the controller controls the RCU of the EMD system to follow the change of the target torque.

The design target torque $T_{d}$ is shown:

$$
T_{d}=\frac{T_{\max }-T_{\min }}{2} \sin (2 \pi f t)+\frac{T_{\max }+T_{\min }}{2}
$$


where $f$ is the frequency of the target torque, $T_{\max }=k_{i}^{2} \omega_{m} /\left(R_{i}+R_{\text {emin }}\right)$ and $T_{\text {min }}=$ $2 k_{i}^{2} \omega_{m} /\left(R_{i}+R_{\text {emax }}\right)$ are the maximum and minimum torques that the EMD system can provide at a 3 certain rotational speed, respectively. $R_{\text {emax }}$ and $R_{\text {emax }}$ are the maximum and minimum external 4 resistance values.

The external resistance value is obtained by:

$$
R_{e}=\frac{k_{i}^{2} \omega_{m}}{T_{d}}-R_{i}
$$

6

The controller to switch the external resistance of RCU at a frequency of $500 \mathrm{~Hz}$ make the electromagnetic torque meet to target torque quickly. As shown in Figure 16 are the curves of target torque and electromagnetic torque when the rotary speed is $1000 \%$, and the frequencies are $1 \mathrm{~Hz}, 10$ $\mathrm{Hz}$, and $20 \mathrm{~Hz}$ respectively.

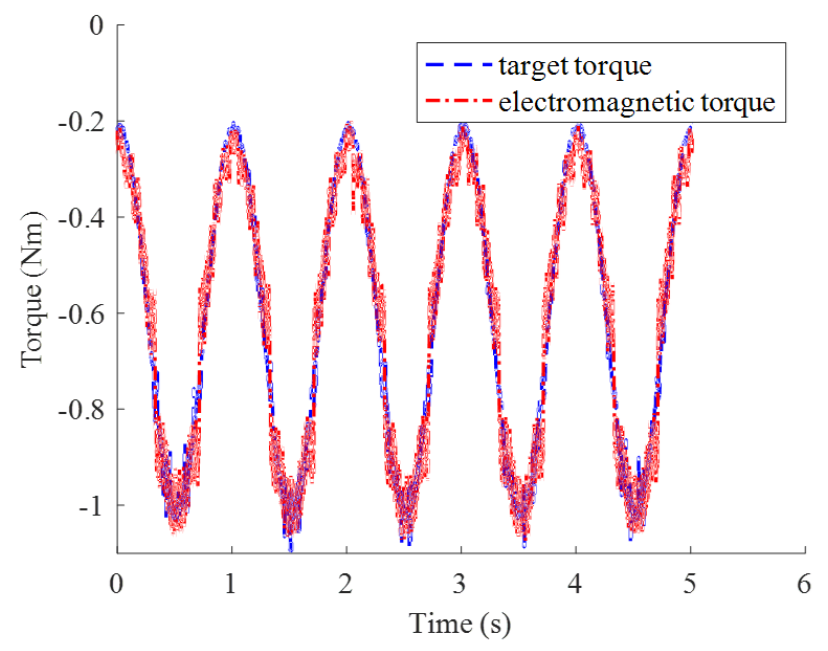

(a) The frequency is $1 \mathrm{~Hz}$

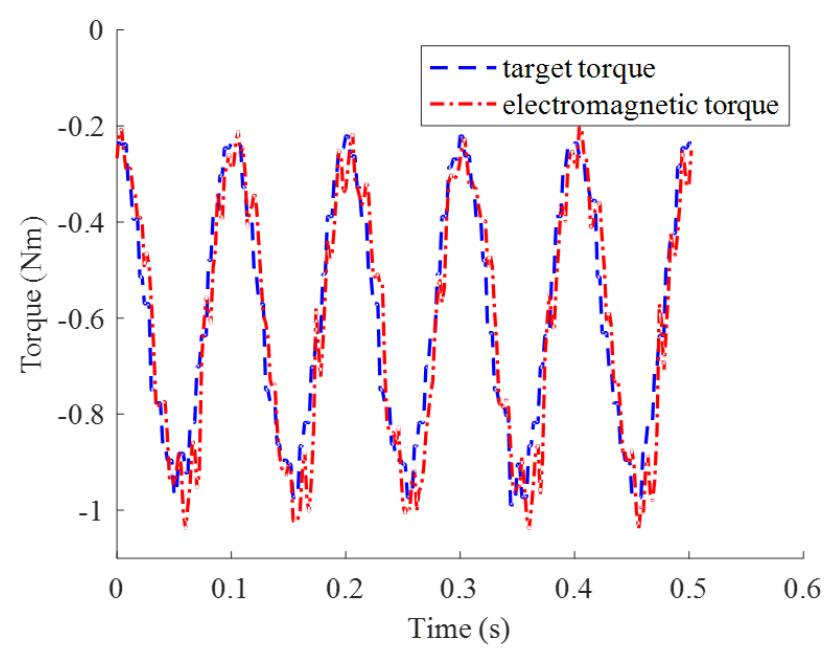

(b) The frequency is $10 \mathrm{~Hz}$ 


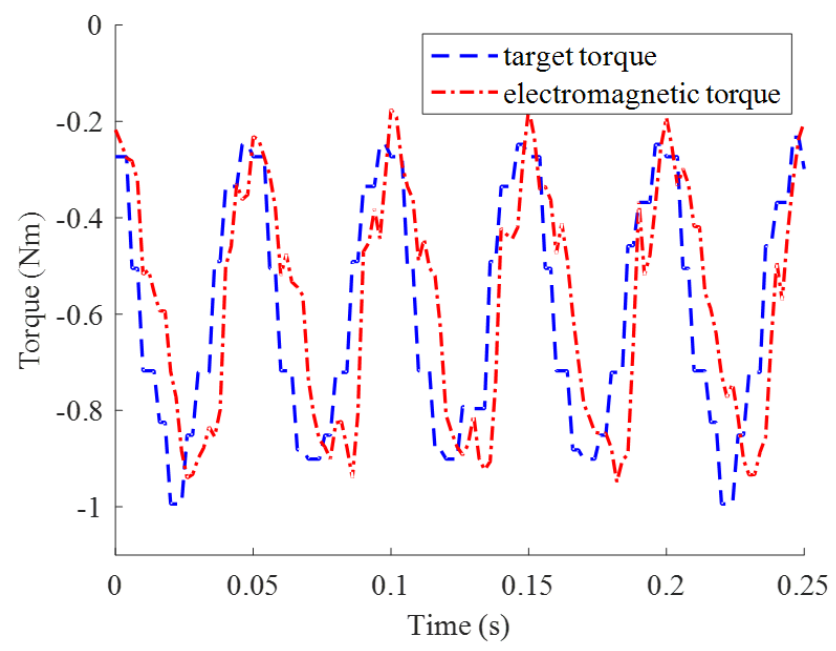

(c) The frequency is $20 \mathrm{~Hz}$

Figure 16. Dynamic torque tracking performance curve.

4

Table 3 The phase difference of torque tracking $\left(^{\circ}\right)$.

\begin{tabular}{c|cccccc}
\hline \hline \multirow{2}{*}{$\begin{array}{c}\text { speed } \\
(\% / \mathrm{s})\end{array}$} & $1 \mathrm{~Hz}$ & $3 \mathrm{~Hz}$ & $5 \mathrm{~Hz}$ & $10 \mathrm{~Hz}$ & $15 \mathrm{~Hz}$ & $20 \mathrm{~Hz}$ \\
\cline { 2 - 7 } 500 & 5.45 & 5.61 & 5.82 & 7.19 & 8.77 & 11.71 \\
1000 & 4.83 & 4.94 & 5.42 & 6.55 & 10.32 & 14.01 \\
1500 & 4.92 & 4.88 & 5.05 & 6.80 & 10.15 & 14.42 \\
2000 & 4.98 & 5.08 & 5.39 & 6.83 & 10.13 & 13.28 \\
\hline \hline
\end{tabular}




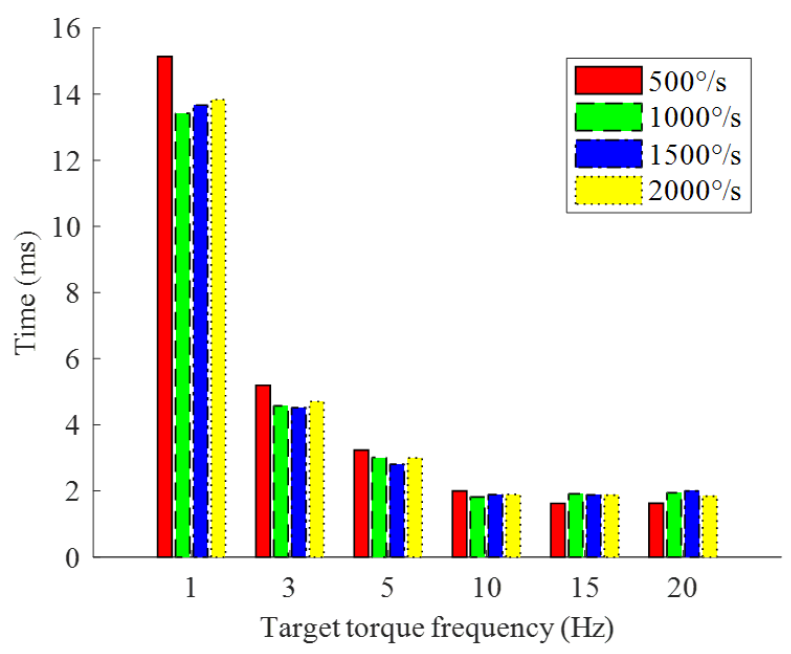

Figure 17. Statistical results of dynamic torque response delay.

The phase difference in table 3 is converted into delay time, and the relationship between response delay time and torque frequency is shown in Figure 17. With the increase of the target torque frequency, the response delay time of the continuous electromagnetic torque changes is significantly decreased. When the target torque frequency reaches $20 \mathrm{~Hz}$, the response of electromagnetic torque only delays $2.35 \mathrm{~ms}$, that is means the EMD system has potential in vehicle suspension vibration reduction.

\section{Controller design and experiment}

In this section, an SMC is designed to achieve real-time control of the seat suspension with an EMD system. A 6-DOF vibration platform simulates two different typical motions of the vehicle body, and the vibration reduction performance of the EMD seat suspension system is compared with a traditional suspension.

\subsection{SMC design}

The SMC is simple, robust and reliable, and is widely used in motion control, especially in deterministic control systems that can establish accurate mathematical models [26-28].

According to the structure of the seat suspension in Figure 1, the angle of the scissor structure can be obtained via:

$$
\theta=2 \arcsin \left(\frac{h_{0}+h(t)}{L}\right)
$$

The rotation speed of the PMSM can be obtained as $\omega_{m}=\dot{\theta} * r_{g}$. The transfer coefficient between the electromagnetic torque and vertical force of seat suspension is defined as $r_{k}=2 / \sqrt{L^{2}-\left(h_{0}+h\right)}$, combining with Equation (1) and (5), we can get: 


$$
F=\frac{r_{k}^{2} r_{g}^{2} k_{t}^{2} \dot{h}}{R_{i}+R_{e}}
$$

In this paper, the seat suspension test is used to verify the torque response performance and controllability of the EMD system. An implementable controller is designed for a simplified singledegree of freedom model with vertical vibration, and the performance of the EMD seat suspension is validated and analyzed with experiments. A mathematical model of the EMD seat suspension is shown in Figure 18, where the vertical excitation of the body is $z_{v}$, the seat and passenger mass is $m_{s}$, the seat spring stiffness is $k_{s}$, the friction is $f_{r}$.

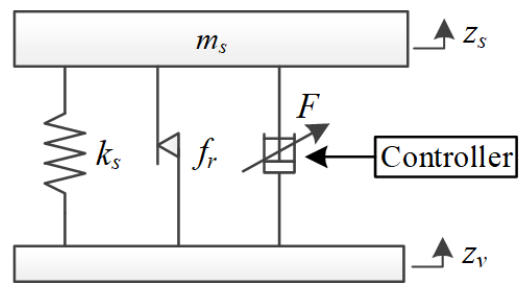

Figure 18. A simplified model of EMD seat suspension.

The seat suspension model of the system is defined as:

$$
m_{s} \ddot{z}_{s}=-k_{s}\left(z_{s}-z_{v}\right)-F-f_{r}
$$

where the friction model $f_{r}=f_{0} \tanh \left(10\left(\dot{z}_{s}-\dot{z}_{v}\right)\right)$ is simplified by the seat suspension in the harmonic vibration test, and $f_{0}$ is the friction coefficient.

In the seat suspension control, the primary objective is the seat vibration. On the other hand, the suspension travel should be in a reasonable range for avoiding the obstruction of drivers' operation. However, for a semi-active seat suspension, its passivity would help to restrict the overlarge suspension travel, and the end-stop will also help to keep a safe condition. In order to verify the force tracking performance and controllability of the EMD suspension through experiments, the directly measurable variables are selected as the SMC controller input and the absolute displacement of the seat $\left(z_{s d}=0\right)$ is selected as the control target.

The tracking error is defined as:

$$
e=z_{s}-z_{s d}
$$

The sliding surface of the system is defined as:

$$
s=c e+\dot{e}
$$

where the $c$ needs to satisfy Hurwitz condition, and $c>0$.

The Lyapunov function is defined as: 


$$
V=\frac{1}{2} s^{2}
$$

The constant rate of approach is adopted:

$$
\dot{s}=-\operatorname{ssgn}(s), \quad \varepsilon>0
$$

Then, the sliding mode controller is designed as:

$$
F=m_{s} c \dot{z}_{s}-k_{s}\left(z_{s}-z_{v}\right)-f_{r}+m_{s} \operatorname{csgn}(s)
$$

3 Therefore,

$$
\dot{V}=s \dot{s}=s\left(c \dot{z}_{s}+\frac{-k_{s}\left(z_{s}-z_{v}\right)-F-f_{r}}{m_{s}}\right)=-\varepsilon|s| \leq 0
$$

According to the LaSalle invariance principle, the closed-loop system is asymptotically stable, when $t \rightarrow \infty$, the $\mathrm{s} \rightarrow 0$, and the convergence rate of $s$ depends on $\varepsilon$.

Combining the Equations (9) and (15), the external resistance value can obtain:

$$
R_{e}=\frac{r_{k}^{2} r_{g}^{2} k_{t}^{2} \dot{h}}{m_{s} c \dot{z}_{s}-k_{s}\left(z_{s}-z_{v}\right)-f_{r}+m_{s} \operatorname{ssgn}(s)}-R_{i}\left(0<R_{e} \leq 50\right)
$$

The EMD seat suspension is a semi-active suspension. The energy source is from the relative motion between the seat and the vehicle. The electromagnetic damping should be between $c_{\max }$ and $c_{\text {min }}$. Therefore, the sliding mode controller should evaluate the required damping in practical application. The basic parameters of EMD seat suspension are given in Table 4. Through software simulation and optimization, the parameters $c$ and $\varepsilon$ of the SMC are finally set to 5 and 0.2 , respectively.

Table 4 The EMD seat suspension basic parameters.

\begin{tabular}{ccc}
\hline \hline parameter & Symbol & Value \\
\hline Gearbox transmission ratio & $r_{g}$ & 20 \\
Seat motion transfer rate & $r_{k}$ & 7.55 \\
Passenger weight & $m_{s}$ & $70 \mathrm{~kg}$ \\
Spring stiffness & $k_{s}$ & $7850 \mathrm{~N} / \mathrm{m}$ \\
Friction coefficient & $f_{0}$ & 80 \\
\hline \hline
\end{tabular}

\subsection{Experimental system and results analysis}

The EMD seat suspension test system based on the 6-DOF vibration platform is illustrated in 16 Figure 19. In the test system, two displacement sensors are used to measure the absolute displacement 17 of the 6-DOF vibration platform and the vibration amplitude of the seat. The absolute seat displacement 18 is the sum of these two displacement values, which is used as the observation of SMC. Similarly, two 


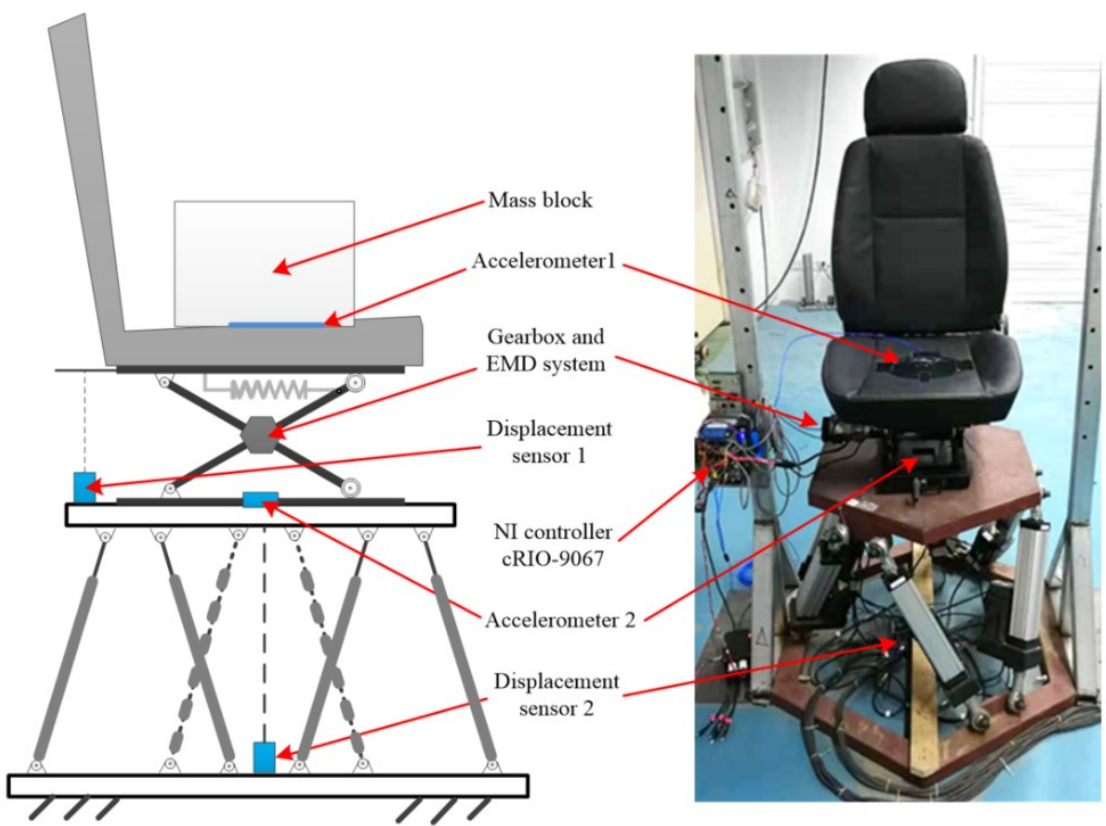

Figure 19. EMD seat suspension test system.

A. Bump vibration test

According to the standard GB/T 4970-2009 for evaluating vehicle driver smoothness [29]. Under the condition that the vehicle passes a small bump with a length of $0.4 \mathrm{~m}$ and a height of $0.04 \mathrm{~m}$ at a speed of $35 \mathrm{~km} / \mathrm{h}$, the vibration curve of the car body can be simulated by a quarter vehicle model. Then, the vibration of the body is implemented by the 6-DOF vibration platform and applied to the seat suspension test.

As shown in Figure 20, the EMD suspension can respond quickly and generate damping force to attenuate the vibration of the seat when a vehicle passes a bump. By comparing the peak value of seat vibration acceleration in Figure 21, the vertical acceleration of the EMD seat decreases about 30\% when the vibration is significant, which indicates a good performance in the shock vibration. Figure 22 shows the comparison curve of the seat suspension travel during the Bump test. It can be seen that the suspension travel of the EMD seat is slightly larger than the conventional seat. In the vibration control of the seat suspension, the suspension travel and acceleration of the seat are relatively contradictory. Both suspension travels are lower than $0.01 \mathrm{~m}$, which can satisfy the practical demand in the safe operation. 


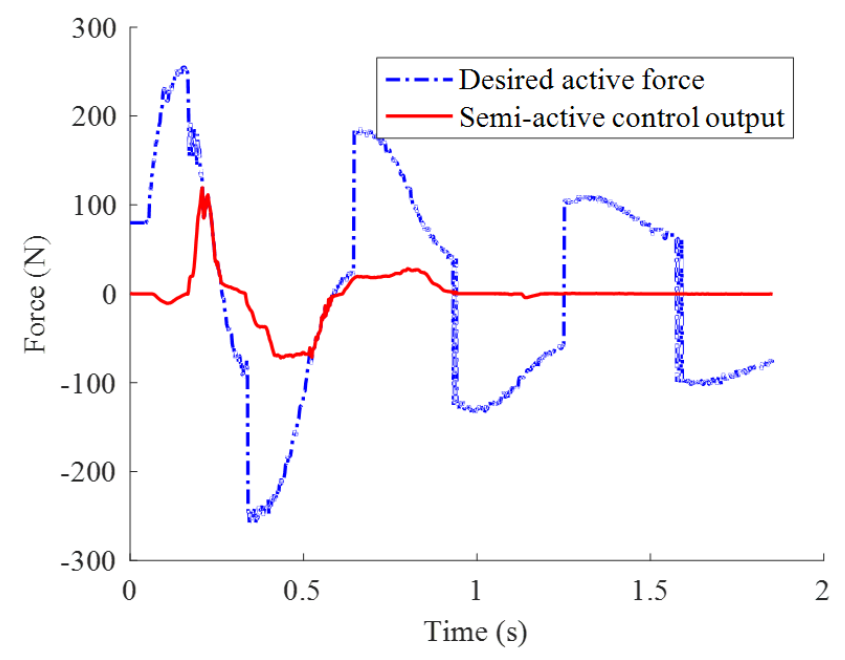

Figure 20. Force track performance at bump excitation.

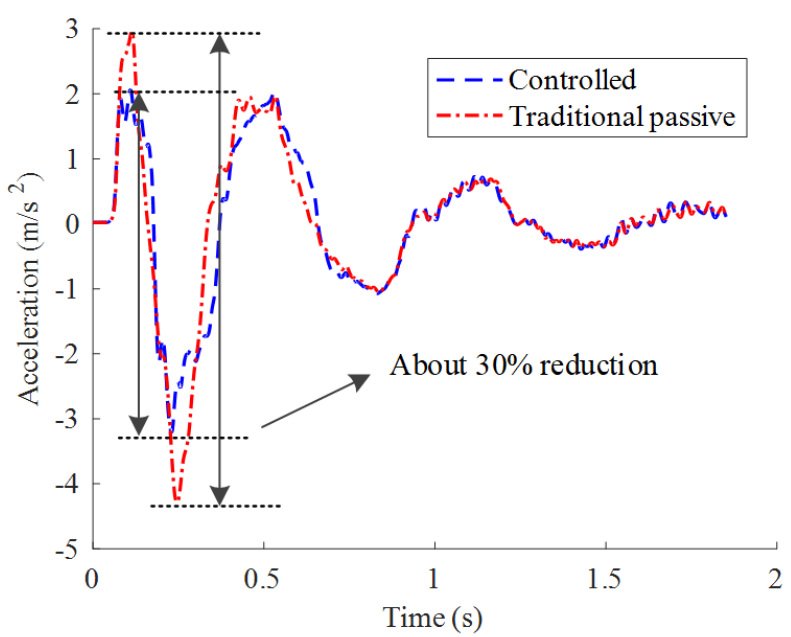

Figure 21. Seat vertical acceleration at bump excitation.

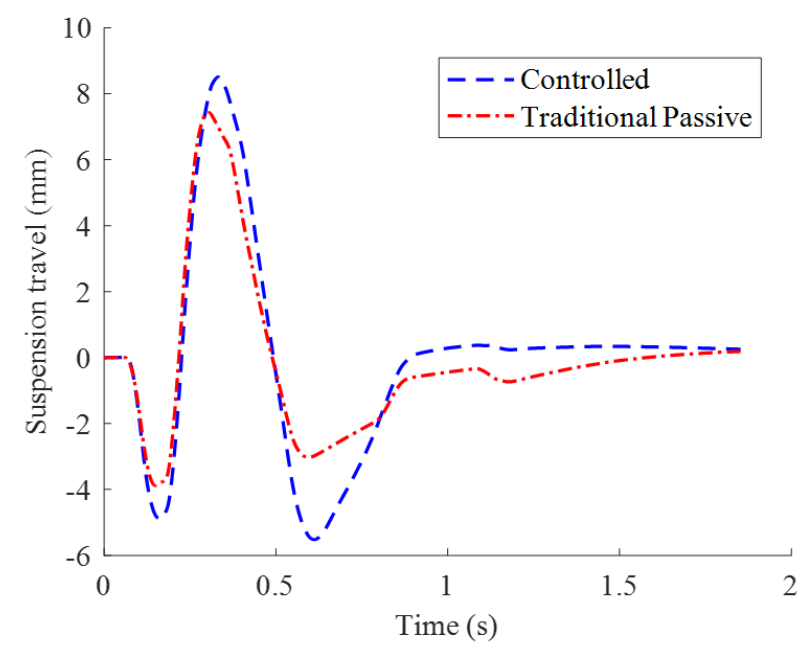

Figure 22. Suspension travel at bump excitation. 
To comprehensively evaluate the time domain performance of EMD seat suspension, a random excitation test is implemented. The random vibration profile is generated through a quarter-car model

3 with random road profile input, which is a typical road condition used to test suspension performance.

4 The interaction of the seat base and the vehicle cab floor is ignored. Thus, the displacement of the 5 sprung mass of the quarter-car model is taken as the vibration input to the seat suspension. Then, the 6 international standard ISO 2631-1 is applied for quantifying performance improvement.

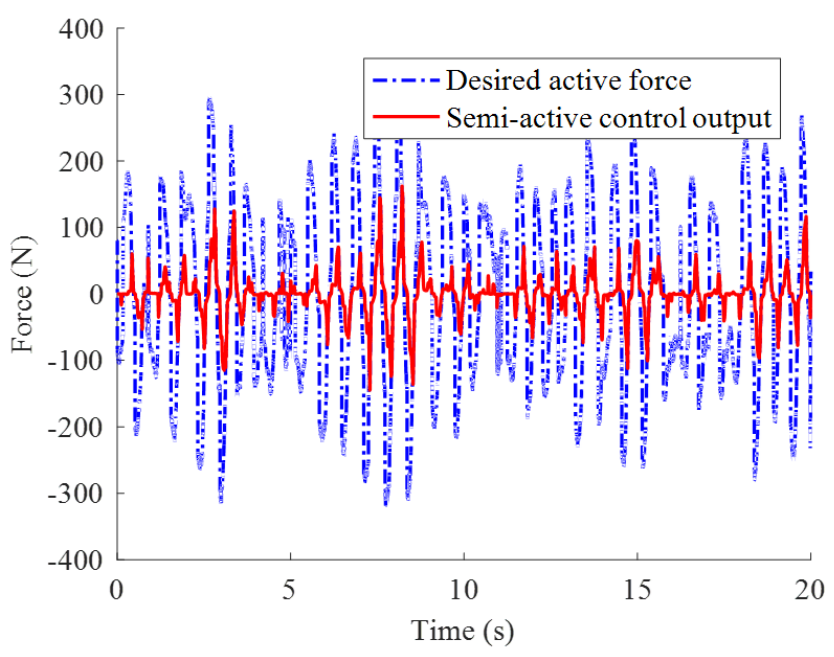

(a)

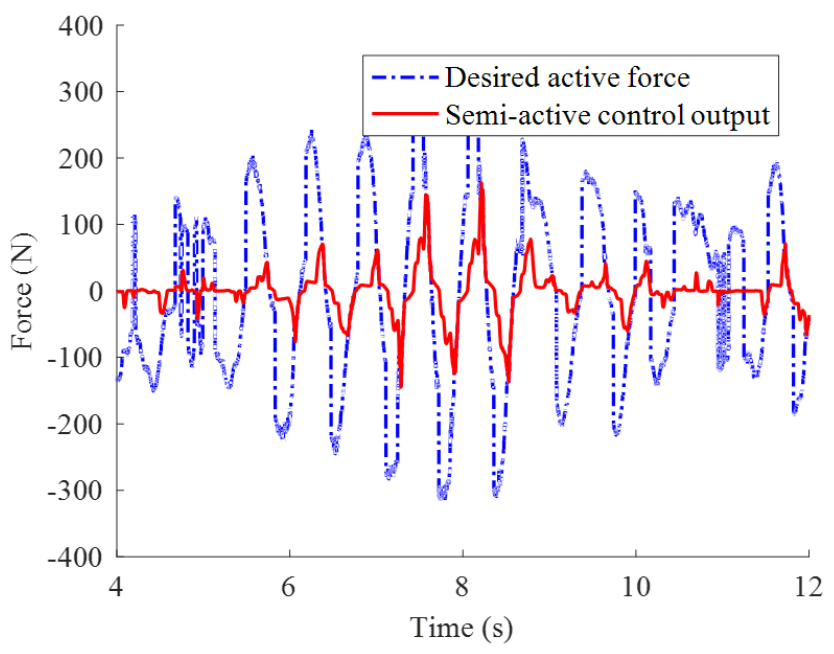

(b)

Figure 23. Force following curve at random excitation.

From Figure 23, the EMD is varying the damping to generate a semi-active force which can meet about $30 \%$ of the requirement of the desired active force and the EMD seat suspension has an apparent 
1 vibration attenuation when the random vibration velocity of the seat is large. Figure 24 is a comparison

2 of the acceleration of the EMD seat and the conventional seat, and Figure 25 is a comparison of the

3 power spectral density (PSD) of the acceleration. It can be seen that the designed EMD seat suspension

4 can effectively reduce the vibration acceleration of the seat and improve the vibration isolation effect,

5 especially at low frequencies.

6

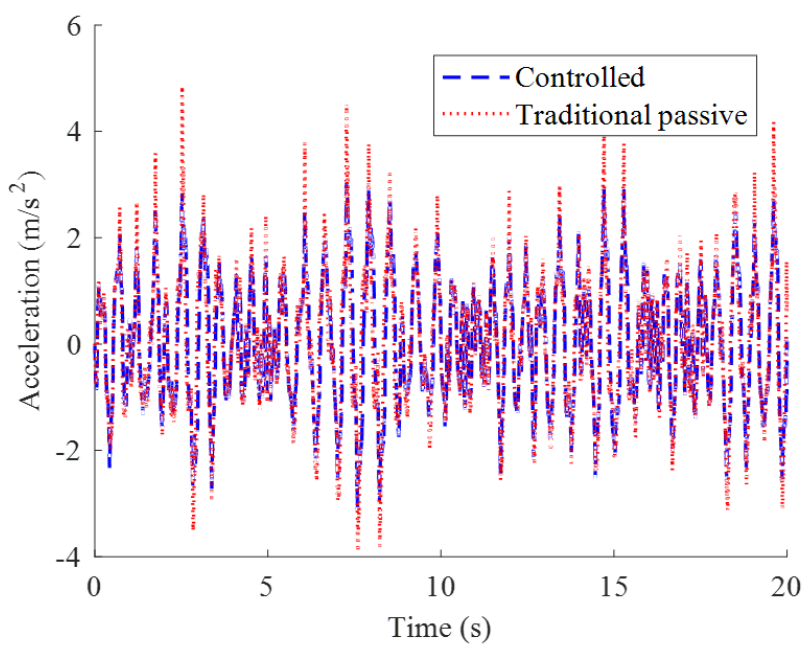

Figure 24. Seat vertical acceleration comparison.

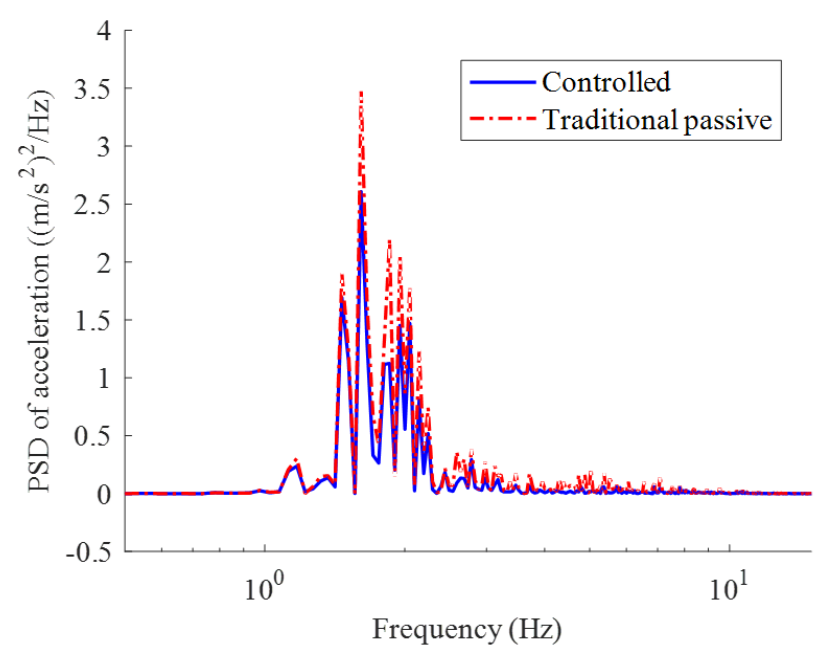

Figure 25. Seat acceleration PSD under random excitation.

According to the standard ISO 2631-1 [30], the FW-RMS acceleration is applied to evaluate the

11 ride comfort because it is calculated by referring that the human body has different responses to different

12 vibration frequencies. The fourth power vibration dose value (VDV) is more sensitive to the peak

13 vibration; it is an additional evaluation method for vibrations. The RMS acceleration, FW-RMS 

respectively.

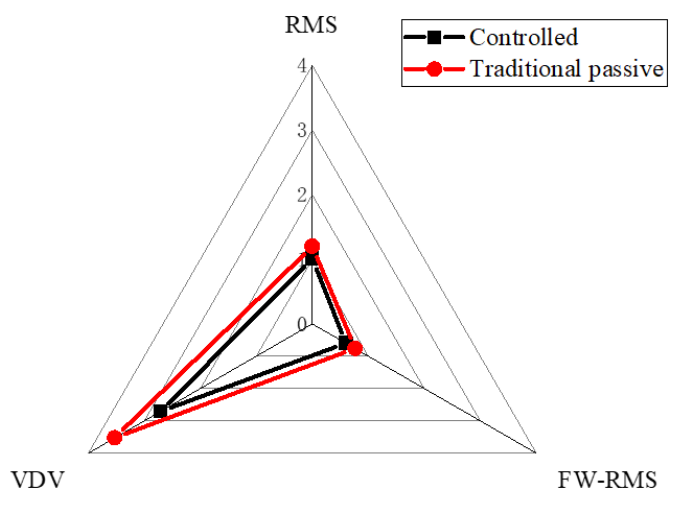

3

4

Figure 26. Evaluation parameters.

As shown in Figure 26, compared with the traditional suspension, the values of the evaluation parameters of EMD system are decreased by $15.87 \%, 21.44 \%$ and $23.14 \%$ regarding RMS acceleration, FW-RMS acceleration, and VDV, respectively.

\section{Conclusion}

In this paper, the RCU has been designed for EMD seat suspension, and the electromagnetic torque response time and torque tracking characteristics of the EMD system have been experimentally studied. Main research results can be concluded as:

(1) The RCU can control the electromagnetic torque of the EMD system.

(2) The electromagnetic torque response of the EMD system is consistent with the current response in the circuit. Hence, we can evaluate the system response by the current measurement.

(3) The test has illustrated the response properties of the EMD system. The response time required by the electromagnetic torque decrease is significantly shorter than the response time of torque increase. The PMSM rotational speed has little influence on the response time of electromagnetic torque. Moreover, the EMD system has excellent performance of dynamic electromagnetic torque tracking. Therefore it can be applied to automobile suspension.

(4) The SMC has been applied to validate the effectiveness of an EMD seat suspension in vibration, and the performance of the EMD seat suspension is better than that of a traditional seat suspension. 
In this paper, the EMD system seat suspension has a scissors structure to transform the linear and rotary movement. With a proper transformation mechanism, the EMD system can apply to other suspensions, such as vehicle suspensions. In future work, we will improve the EMD system performance with an advanced controller, and the potential application of EMD system on automobile suspension will be verified.

\section{Acknowledgment}

The research is supported by the National Natural Science Foundation of China (51675152) and the Ministry of Science and Technology (2018YFB0105505-03).

\section{Reference}

[1] M.H. Pope, D.G. Wilder, M.L. Magnusson, A review of studies on seated whole body vibration and low back pain, Proceedings of the Institution of Mechanical Engineers, Part $\mathrm{H}$ : Journal of Engineering in Medicine, 213(6) (1999) 435-446.

[2] I.M. Virtanen, J. Karppinen, S. Taimela, J. Ott, S. Barral, K. Kaikkonen, O. Heikkilä, P. Mutanen, N. Noponen, M. Männikkö, O. Tervonen, A. Natri, L. Ala-Kokko, Occupational and Genetic Risk Factors Associated With Intervertebral Disc Disease, 32 (2007) 1129-1134.

[3] S.-B. Choi, M.-H. Nam, B.-K. Lee, Vibration Control of a MR Seat Damper for Commercial Vehicles, Journal of Intelligent Material Systems and Structures, 11 (2016) 936-944.

[4] S. Sun, X. Tang, J. Yang, D. Ning, H. Du, S. Zhang, W. Li, A new generation of magnetorheological vehicle suspension system with tunable stiffness and damping characteristics, IEEE Transactions on Industrial Informatics, (2019) 1-1.

[5] A.L. Morales, A.J. Nieto, J.M. Chicharro, P. Pintado, A semi-active vehicle suspension based on pneumatic springs and magnetorheological dampers, Journal of Vibration and Control, 24 (2016) 808-821.

[6] I. Maciejewski, T. Krzyzynski, L. Meyer, H. Meyer, Shaping the vibro-isolation properties of horizontal seat suspension, Journal of Low Frequency Noise, Vibration and Active Control, 36 (2017) 203 213.

[7] I. Maciejewski, T. Krzyzynski, H. Meyer, Modeling and vibration control of an active horizontal seat suspension with pneumatic muscles, Journal of Vibration and Control, 24 (2018) 5938-5950.

[8] M. Gong, H. Chen, Variable damping control strategy of a semi-active suspension based on the actuator motion state, Journal of Low Frequency Noise, Vibration and Active Control, (2019).

[9] L.T. Danh, K.K. Ahn, Active pneumatic vibration isolation system using negative stiffness structures for a vehicle seat, Journal of Sound and Vibration, 333 (2014) 1245-1268.

[10] Y.J. Cha, A.K. Agrawal, S.J. Dyke, Time delay effects on large-scale MR damper based semi-active control strategies, Smart Materials and Structures, 22 (2013) 13.

[11] T.-H. Lee, S.-B. Choi, On the response time of a new permanent magnet based magnetorheological damper: experimental investigation, Smart Materials and Structures, 28 (2019).

[12] D.S.Yoon, Y.J.Park, S.B.Choi, An Effect of the Time Response of MR Damper to the Vehicle Suspension Performances, ACTUATOR 2018: 16th International Conference on New Actuators, (2018) 25 28.

[13] J.-H. Koo, F.D. Goncalves, M. Ahmadian, A comprehensive analysis of the response time of MR dampers, Smart Materials and Structures, 15 (2006) 351-358.

[14] H. Sahin, P.R. Tao, P.N.M. Wereley, F. Gordaninejad, X. Wang, Y. Liu, Response time of magnetorheological fluids and magnetorheological valves under various flow conditions, Journal of Intelligent Material Systems and Structures, 23 (2012) 949-957.

[15] Z. Strecker, J. Roupec, I. Mazurek, M. Klapka, Limiting factors of the response time of the magnetorheological damper, Int. J. Appl. Electromagn. Mech., 47 (2015) 541-550. 
[16] Z. Strecker, I. Mazůrek, J. Roupec, M. Klapka, Influence of MR damper response time on semiactive suspension control efficiency, Meccanica, 50 (2015) 1949-1959.

[17] Z. Strecker, J. Roupec, I. Mazurek, O. Machacek, M. Kubik, M. Klapka, Design of magnetorheological damper with short time response, Journal of Intelligent Material Systems and Structures, 26 (2015) 1951-1958.

[18] M.A.A. Abdelkareem, L. Xu, X. Guo, M.K.A. Ali, A. Elagouz, M.A. Hassan, F.A. Essa, J. Zou, Energy harvesting sensitivity analysis and assessment of the potential power and full car dynamics for different road modes, Mechanical Systems and Signal Processing, 110 (2018) 307-332.

[19] H. Wang, C. He, S. Lv, H. Sun, A new electromagnetic vibrational energy harvesting device for swaying cables, Applied Energy, 228 (2018) 2448-2461.

[20] R. Zhang, X. Wang, Parameter study and optimization of a half-vehicle suspension system model integrated with an arm-teeth regenerative shock absorber using Taguchi method, Mechanical Systems and Signal Processing, 126 (2019) 65-81.

[21] A. Gonzalez-Buelga, L.R. Clare, S.A. Neild, S.G. Burrow, D.J. Inman, An electromagnetic vibration absorber with harvesting and tuning capabilities, Structural Control and Health Monitoring, 22 (2015) 1359-1372.

[22] A. Gonzalez-Buelga, L.R. Clare, S.A. Neild, J.Z. Jiang, D.J. Inman, An electromagnetic inerter-based vibration suppression device, Smart Materials and Structures, 24 (2015).

[23] J.-Y. Li, S. Zhu, Versatile Behaviors of Electromagnetic Shunt Damper With a Negative Impedance Converter, IEEE/ASME Transactions on Mechatronics, 23 (2018) 1415-1424.

[24] D. Ning, H. Du, S. Sun, W. Li, W. Li, An Energy Saving Variable Damping Seat Suspension System With Regeneration Capability, IEEE Transactions on Industrial Electronics, 65 (2018) 8080 -8091.

[25] D. Ning, S. Sun, H. Du, W. Li, N. Zhang, Vibration control of an energy regenerative seat suspension with variable external resistance, Mechanical Systems and Signal Processing, 106 (2018) 94-113.

[26] H. Li, J. Yu, C. Hilton, H. Liu, Adaptive Sliding-Mode Control for Nonlinear Active Suspension Vehicle Systems Using T-S Fuzzy Approach, IEEE Transactions on Industrial Electronics, 60 (2013) 33283338.

[27] V.S. Deshpande, B. Mohan, P.D. Shendge, S.B. Phadke, Disturbance observer based sliding mode control of active suspension systems, Journal of Sound and Vibration, 333 (2014) 2281-2296.

[28] D. Ning, S. Sun, L. Wei, B. Zhang, H. Du, W. Li, Vibration reduction of seat suspension using observer based terminal sliding mode control with acceleration data fusion, Mechatronics, 44 (2017) 71 83.

[29] GB/T, Test method for the vehicle ride comfort, 2009.

[30] ISO, Mechanical Vibration and Shock-Evaluation of Human Exposure to Whole-body VibrationPart 1:General Requirements, 2015. 